\title{
Holistic Appraisal of and Approaches to Agriculture and Food Policy
}

\author{
Adhikarla Suryanarayana Rao \\ Department of Biotechnology, Bharathidasan University, Tiruchirappalli, India \\ Email address: \\ asraobio@gmail.com

\section{To cite this article:} \\ Adhikarla Suryanarayana Rao. Holistic Appraisal of and Approaches to Agriculture and Food Policy. International Journal of Applied \\ Agricultural Sciences. Vol. 6, No. 5, 2020, pp. 118-123. doi: 10.11648/j.ijaas.20200605.13
}

Received: September 1, 2020; Accepted: September 19, 2020; Published: September 25, 2020

\begin{abstract}
Total number of countries and territories together are put at 235. Apparently, single blanket recommendation is not possible but one has to think of custom made and tailored solutions/policies-country and territory wise- and within country and territory wise. "How many are to be fed" and "How many are needed to feed" ? How much land needs to be ear marked for agriculture and animal husbandry? Statistics must be viewed from all angles while framing policies Viz; Nature of political governance; Total land area; Nature of the varies types of land available; Climatic conditions; Total population; Population density; Food habits; Availability of resources for agriculture and animal husbandry and for otherwise living. An integrated approach of tailor made strategies, creating strong awareness, incentives and disincentives, due monitoring and follow up must be there. This is required particularly in highly populated regions of the world apart from thinking of different strategies to increase food production and ensure food security. As the system of governance varies with the country, measures and the manner and extent of their implementation can vary. Government should encourage expertise and invest money to develop better agricultural and animal husbandry production and food distribution and food security logistics. Plants can be exploited for needs other than food but food is the first requirement. Climate change, Global warming, Sustainability and Organic Agriculture are of considerable complexity, futuristic, considerable dualities, multifaceted and inter-related and requires a critical analysis. Past, present and future scenarios have to be duly appraised to people of respective countries by the respective Governments, UN and other International Organizations. Irrespective of the state of affairs, the following measures are definitely required Viz; population control, avoiding wars and social conflicts and political instability and clean and healthy and contented life styles. Due restraints need to be followed.
\end{abstract}

Keywords: RDA and Food Habits, Custom Made Policies, Farmers Feedback, Climate Change and Agriculture, Alternative Technologies, Multifaceted View of Classified Statistics, Developed Versus Developing Countries, Role of Nations and UN

\section{Introduction and Background}

\subsection{Early Warnings About Population Problem}

Norman Borlaug, the father of the Green Revolution as early as in 1970, warned the world duly about the magnitude and menace of the "Population Monster" and further cautioned that food should not be taken for granted [1].

\subsection{Population Growth in the World, China and India}

Did man behaved rationally as Borlaug expected?? At world level--“No". In some cases -"Yes". World population increased from 3.68 billion to 7.9 billion today and further projected to increase to 9 billion plus by 2050 . Just two countries India and China now constitute nearly $40 \%$ of the world's population.. Hence, food production and security assumes a greater significance.

\section{Strategies for Food Production and Safety}

\subsection{Due Appraisal of People of All Categories}

Every Government should appraise the people of all 
categories about the state of affairs of its nation and the world-past, present and futuristic--and should be prepared to enforce laws for implementing the strategies for food production and food security. All target groups should be duly appraised about the various resources of the country and the need for self sufficiency in food.

\subsection{Natural Constraints and Disasters}

Earth's surface is $71 \%$ water of which only $2.4 \%$ is fit for direct human consumption and agriculture. Of the $29 \%$ land surface nearly one-third is desert area [2]. Total population, per capita availability, nature of the agricultural land, climatic conditions and food habits vary across different countries. Statistics as above has to be analyzed for every country /zones to frame useful policies on agriculture and animal husbandry.

During natural disasters at any time and wars etc., food distribution becomes a serious problem. Hence, Governments should make due provision for storage of a sufficient stock of food material.

\subsection{RDA (Recommended Dietary Allowance) for Different Target Groups}

A strong and convincing awareness program is required in appraising about RDA (Recommended Dietary Allowance) for various nutrients required for persons with respect to age, gender, health status etc. and as to how to get the required food items economically. [3, 4].

\subsection{Concern for Land Usage and Deforestation and Exploitation of Desert Area}

Farmers/owners of the agricultural lands should not be allowed to keep them fallow or diverted towards nonagricultural purposes. Destruction of forests also is detrimental in many ways. which leads to loss of forest products for human consumption, gross displacement and hardships for forest/tribal dwellers. Only for pressure of food forest land may be diverted to staple crops. [5].

Nearly one-third of the land surface is desert area and any edible and non-edible crops and different animals are grown to varying extent in these deserts. and is distributed over many countries/continents. Saudi Arabia, Israel, Australia, Southern California etc are some promising examples [6].

\subsection{Demographics and Planning of Agriculture and Animal Husbandry}

Total population, population contributing to agriculture, land available for agriculture and animal husbandry varies a lot across the countries. Hence the burden varies and accordingly strategies need to be followed.

Every country needs to earmark land for agriculture and animal husbandry keeping in view the agro-climatic conditions, food habits and cost of cultivation and remain self sufficient [7]. In addition to main agriculture and animal husbandry there had been considerable interest from in mushroom cultivation and vermiculture /vermicomposting in certain regions Both have considerable scope for expansion in future $[8,9]$. Mushroom cultivation is one of the most significant agriculture business in the world with US, China, Italy and Netherlands being the top producers and is so in many parts of India. This adds to the income of the concerned. However, mushroom cultivation is only a supplement and not a replacement for the RDA/ staple diet.

Vermicompost contains water-soluble nutrients and is an excellent, nutrient-rich organic fertilizer and soil conditioner. Large-scale vermi-composting is practiced in Canada, Italy, Japan, India, Malaysia, the Philippines, and the United States.

\subsection{Bridging the Gap Between Producer and Consumer}

Difference between the price which a farmer gets and which a consumer pays can be too wide and strategies need to be evolved to drastically reduce this difference. A major reason is the "Middlemen". This needs to be analyzed and remedial measures to be taken so as to protect both the farmers and the consumers [10, 11]. Losses during long distance transport and \& storage and food wastage should be $\mathrm{a} /$ minimized $[12,13]$.

\subsection{Bridging the Gap of Potential and Actual Yields}

Since long it has been recommended that "Bridging the gap between Potential Yield and Actual Yield" can be a major leap in food production as this gap is too wide across countries in the world for the same crop and different for different crops. Many reasons for yield gap exist which need to be tackled Viz; ineffective extension programs and inadequate availability of financial assistance, quality inputs, water availability labor and/or automation.[14]. There is a need to understand thoroughly the partitioning of biomass among all plant parts with the hope evolving strategies to increase yield.

\subsection{GM (Genetically Modified) Crops}

Number of GM (Genetically Modified/ Transgenic) crops and area under GM crops had been increasing since the first introduction of GM crop in 1996. However, only four GM crops constitute almost all of the area Viz; Soybean, corn (maize), cotton and five countries constitute $90 \%$ of the cultivation with USA leading iii) Several countries do not grow but do import GM crops. Overall GM crops constitute only $10-12 \%$ of the total land used for primary crops. India's GM Bt cotton amounts to nearly $7 \%$ of the total area used for primary crops. Most area of GM crops is concerned with insect and herbicide resistance. They are not directly related to yield determining processes but otherwise contribute to increased yield by crop protection measures and facilitate the farmers in lessening their burden of crop protection and cost of cultivation. Some transgenics are concerned with nutritional benefits and production of pharmaceuticals.

Benefits and harmful effects are always being discussed. A recent mishap in this context is the unexpected extreme devastation of GM Bt Cotton (resistant to Boll worm) in India by white flies resulting in a huge loss of 4,200 crore (42 
billion) Indian rupees. [15-17].

\section{Long Term Goals}

\subsection{Desalinization of Sea Water}

Many countries particularly Israel, Saudi Arabia etc. have successfully carried the process of desalination. In terms of percentage Israel has been very successful as $55 \%$ of its domestic fresh water requirement is met by desalination. However, still desalination accounts for only one percent of world's fresh water. According to FAO estimates, by 2025 nearly 2 billion people may not have enough drinking water to satisfy their daily needs. Hence, enormous potential exists for desalination. The primary constraint in increasing the potential is energy apart from the associated technology. Hence, another long term goal is to use naturally available solar energy for desalination and use this water for drinking and irrigation purposes. [18, 19].

\subsection{Sea \& River Food and Their Pollution}

Oceans supposed to contribute about $14-16 \%$ of the animal protein consumed worldwide and over one billion people are supposed to rely on seafood as their primary source of animal protein. Japan has one of the highest consumption and they view seafood not just as a source of food but also as something that contributes to health and longevity. Similarly food from other water bodies like rivers and lakes are being used. Unfortunately, a major threat to the water bodies is pollution. Several causes of pollution have been identified Viz; toxic chemicals from industries, agricultural effluents; oil spills, radioactive material, plastics, acid rain, polluted rivers merging into the ocean and because of light, thermal and noise pollution too. [20,21].

\subsection{Efficient Use of Fertilizers and Water}

Controlled release of fertilizers, water /irrigation-smart fertilizer \& smart irrigation-- to crops can save both water and fertilizer and expenditure and can reduce environmental contamination. Controlled release of water by sprinkler and drip irrigation systems and saving huge amounts of water and increased production has been successfully demonstrated in Israel and other countries. Controlled release of fertilizers smart fertilizers - is and is yet to take off on par with controlled irrigation but is promising. Expanding the efforts in this direction are recommended $[22,23]$.

\subsection{Urban Agriculture}

Urban agriculture is supposed to be practiced by 800 million people worldwide utilizing roof tops, kitchen garden, walls of the houses, balconies, indoor plants and open spaces. Of course Government maintains some parks for public and maintains trees on road sides. These trees mainly serve the purpose of providing shade, aesthetic appeal and reduce air pollution and not so much for any food consumption either of animals or humans. It remains to be reflected how particularly peri-urban/sub-urban agriculture can be protected and developed in view of facilitating the marketing by farmers in urban areas. [24, 25].

\subsection{Robots and Drones}

Robots including drones in agriculture are promising to carry out a multitude of tasks and have been successfully employed hitherto and holds a great promise for future.. Robots market potential is estimated to be $\$ 11.58$ billion by 2025 and can further increase. [26, 27].

\subsection{Climate Change, Global Warming, Sustainability and Organic Agriculture}

The above topics/aspects / practices are of considerable complexity, futuristic, considerable dualities, multifaceted and inter-related. Here, a broad view is given without compromising the essence and to duly assess the situation facilitate future course of action by all concerned [28-35].

\subsubsection{Global Warming and Climate Change and Agriculture \\ i General Introduction}

Climate has been changing even before man evolved and particularly to mention even before aerobic organism evolved. Both in long past and now all types of natural disasters were occurring. The disastrous phenomenon of El Nino and La Nina which had been occurring/ occurs frequently adversely affecting the coastal sea life. So a more reasonable inference is, probably man is just one component of so many changes occurred in the past and for so many changes in the future.

Effect is projected on agriculture and on live stock and fisheries. As the projections are made till the year 2100 it is not an aspect to be easily comprehended. How climate change makes a difference needs to be carefully monitored for some more time to draw indisputable conclusions for different places and accordingly follow a concrete course of action. The effect of climate on agriculture is supposed to be related to variabilities in local climates rather than in global climate patterns. Hence, every country and every region in a country has to be analysed separately and generate information relevant to that region to accordingly take a course of action. [28-31].

ii Causes

Principal cause has been attributed to the build up of GHG's (Green House Gases) Viz; $\mathrm{CO}_{2}$, methane, nitrousoxide, hydrofluorocarbons/chlorofluorocarbons (HFCs/CFC's), perfluorocarbons (PFCs) and sulfur hexafluoride. Water vapour also is considered as a GHG. Individually considering agriculture and animal husbandry can contribute to more than $50 \%$ of methane emission, nearly $80 \%$ of nitrous oxide emissions and almost all of $\mathrm{CO}_{2}$ concerned with land use. Together, Agriculture and animal husbandry was estimated to contribute to nearly $20 \%$ of annual increase in GHG (Green house gases).

The environmental effects of carbon dioxide are of significant interest as it makes up the largest share of the greenhouse gases contributing to global warming and climate 
change. Twenty one countries have been ranked for $\mathrm{CO}_{2}$ emissions both on total basis and per capita basis. USA had the maximum followed by China, India and Russian Federation respectively. These four countries are responsible for $55 \%$ of the total emissions, with just two countries USA and china contributing to $43 \%$. Another 13 countries cumulatively contribute to $24 \%$ while the rest of the vast number of the countries in the world cumulatively contribute $21 \%$. On a per capita basis, India emits the least-among the 21 countries -- though its total emission is high ranking third. It is clear from this data that the responsibility of reducing $\mathrm{CO}_{2}$ emissions is widely different among countries.

iii Consequences

Both negative and positive effects are projected: a) increased rainfall and paradoxically water shortages also. Similarly both increase in drought and flood situations also; b) decrease in crop and livestock productivity and fisheries; c) glaciers melting; d) increase in pest incidence and emergence of new pests and diseases both in plants and livestock; e) increase in sea levels affecting coastal life f) thawing of permafrost and increase in the intensity of hurricanes. Though the climate changes have the above mentioned negative effects, they are not uniform but highly variable. Positive effects include increase in $\mathrm{CO}_{2}$ increasing yield of certain crops in certain regions provided all other required inputs are provided particularly of C3 crops. Similarly, increase in rainfall can be beneficial in certain regions. And increase in temperatures would be beneficial in low temperature regions.

iv Mitigation Measures

For a long term the following major mitigation measures have been suggested: a) Drastic reductions in fossil fuel consumption b) Development of more resistant crop varieties to biotic and abiotic stresses c) Reducing pollution of water bodies -rivers, lakes and seas d) Development of Solar energy technology e) Better water management practices. f) Decrease in chloroflurocarbons and halons responsible for the destruction of ozone layer

\subsubsection{Sustainable Agriculture and Organic Farming}

\section{i General Introduction}

In agriculture sustainability primarily aims at fulfilling the present food needs of the farmers and consumers without compromising the food needs of farmers and consumers of the future generation and to always protect environment. A caution in this type of definitions is, plants produce many products other than food for human use. As food is the most basic need the emphasis is made primarily on food.

An alternative terminology is "Zero Budget Natural Farming (ZBNF)" which is a farming practice that believes in natural growth of crops without adding any synthetic fertilizers and pesticides or any other foreign elements. Locally available organic inputs used for seed treatments and other inoculations. La Vía Campesina is an international farmers organization founded in 1993 in Belgium, formed by 182 organizations in 81 countries concerned with peasants welfare and movements and strongly supports family-farm- based sustainable agriculture, In this practice farmer has lower cost of inputs - more suitable for poor farmers-- and thus has better capacity to increase the incomes. At the same time, ZBNF crops helps in retaining soil fertility and is climate change resilient.

There is a need to further increase food production to meet adequately the demands of the existing population and to meet the demands of the future population. In case of organic production livestock is supposed to be fed on grains, hay, pastures etc. which are raised exclusively organically. By 2030 EU wants to make organic agriculture $25 \%$ of their total agriculture. Similarly, Australia also has been carrying out organic farming in a large way. This target is not possible for all countries, because of differences in population, land area, economic prosperity and food habits. Hence, unless alternative systems assures food sufficiency, then only the countries can afford to follow them [32-35].

ii Merits and Demerits

The use of inorganic is relatively recent in the history of human civilization. Even now at the world level only 1-2\% of world's food is produced by organic methods. Hence, it is definitely a long way to make it a significant share of total food production at global level.

The following are considered/visualized as major advantages of the organic farming: a) no/less chemicals are used with synthetic fertilizers replaced by different organic manures recycled from the farm itself and pesticides \& herbicides replacing biological control methods and/or manually rather than using pesticides \& herbicides. Hence the above is considered environmental friendly by reducing health risks to farm workers because of non/less exposure of toxic chemicals to farm workers. Similarly, other chemicals like anti-microbials and growth hormones are not/less used; less chemical residues in soil, ground water and on edible parts thus maintaining soil health, and reducing ground water pollution and air pollution. While the mechanism is yet to be understood some organic food is claimed to be more nutritious and tasty b) That GMO's are not used is cited as an advantage. However, this is contradictory to the pro-GM crops activists who strongly recommend GM crops and cite the same advantage of being environment friendly as in the case of pest resistant GM crops.

Major disadvantages include: extremely difficult or even said as impossible in highly populated regions to produce as much required food solely by organic farming and hence it cannot meet the demands of the existing and growing population. b) Available organic matter is just not sufficient to meet the requirements of the crops c) more manual labor requiring e) greater monitoring of crops is required and the farmers have to acquire the required specialized knowledge for organic farming f) legally organically produced food has to be labeled which can be a cumbersome process g) while farmers not getting subsidies for organic agriculture is cited as a disadvantage it cannot / should not be so be so if governments themselves recommend organic agriculture. 


\subsection{Role of UN and Other Organizations}

The way UN had MDG (Millennium Development Goals) and SDG (sustainable Development Goals) it should have NWG "No War Goal till 2050", the year which is quoted by many in their articles dealing with population growth and food requirements. This goal should include both wars between the countries and wars/social conflicts within the countries. Only then people and nations, particularly from poor and developing nations can have some breathing time to take care of agriculture and other welfare and development measures. Lester Brown of World Watch Institute, Washington, told long back that nations should drastically reduce their defense expenditure and use this money for welfare and development. They should solve their problems by negotiations and live in peace. Unfortunately it was/is not happening. Hence, UN should declare NWG and see to it that it is maintained.

A master plan need to be evolved for these Black African countries by the UN organizations and other international organizations. Forty six of African's 54 countries are categorized as Sub-Saharan. Even their cumulative population of 1.08 billion is less than of India and China and much less if single country from the above is compared with Indian and China which are also single countries. Their total land area also is more. Hence one can be optimistic of improving the conditions in at least some of the Sub-Saharan countries [36, 37].

UN and other International organization should conduct constant awareness programs and collect the feedback of farmers from all the countries of the world. Further planning should always be based on current and adequate feedback from farmers and others concerned with agriculture and animal husbandry. UN can ensure philanthropic aid from less populated and food surplus countries and can also duly persuade corporate --national and multinational-to contribute towards food production and security as a part of their social responsibilities.

\section{Conclusions}

Single blanket recommendation is not possible for all the 235 countries and territories but one has to think of custom made and tailored solutions. In every country an integrated approach is required. Recommendations/ Strategies/ Planning need to be tailor made to every country and to every region within the country as required keeping in view the nature of governance, population, agro-climatic conditions, food habits, relative needs of agriculture and animal husbandry, peoples attitudes, economic status, educational status, total land area, total arable land / nature of the varies types of land available, total population, ratio of rural to urban population, other needs that plants/crops can serve etc. Every nation should convincingly appraise their respective people about the past and present state of affairs and future scenarios on all relevant aspects. Hence, there is a strong need to conduct awareness programs from time to time. Desalinization of sea water, exploitation of desert areas, control of marine and river pollution should be actively pursued. Role of GM crops and alternative technologies like increasing the efficiency of fertilizer and water use, use of robots and drones, and urban agriculture need to be duly assessed and practiced. Climate change, Global warming, Sustainability and Organic Agriculture are of considerable complexity, futuristic, considerable dualities, multifaceted and inter-related and requires a critical analysis. Past, present and future scenarios have to be duly appraised to people of respective countries by the respective Governments, UN and other International Organizations. Irrespective of the state of affairs, the following measures are definitely required Viz; population control, avoiding wars and social conflicts and political instability and clean and healthy and contented life styles. Due restraint need to be followed. Role of individual nations, corporate and UN and its associated organizations, individual nations corporates can play a great role.

\section{Acknowledgements}

I sincerely thank Dr. Anil Kumar, and PhD Students Prabhas and Karthik for sparing their laptop and also providing me with the grammarly software. My sincere thanks are also to Mr. Raja who had been delivering food at home during the present Corona crisis.

\section{References}

[1] Norman Borlaug Quotes-Copyright (C) 2001 - 2020 BrainyQuote- https://www.brainyquote.com/auhtors/normanborlaug-quotes.

[2] https://en.wikipedia.org/wiki/Water_distribution_on_Earth-Water distribution on earth--April 2020.

[3] DRI Activities Update - March (2020) https://health.gov/ourwork/food-nutrition/dietary-reference-intakes-dris/activitiesupdate.

[4] Appendix 7. Nutritional Goals for Age-Sex Groups Based on Dietary Reference Intakes and Dietary Guidelines Recommendations (2015-2020) https://health.gov/ourwork/food-nutrition/2015-2020-dietaryguidelines/guidelines/appendix-7/.

[5] Africa Deforestation-WWF- World Wide Fund for nature (1986/2020) https://wwf.panda.org/our_work/forests/deforestation_fronts2/ deforestation_in_the_congo_basin.

[6] https://en.wikipedia.org/wiki/Desert_farming --- Desert farming-- Page Last updated-11 Feb. 2020.

[7] Agricultural land (\% of land area) (2019) The World Bank. https://data.worldbank.org/indicator/ag.Ind.agri.zs.

[8] Commercial Mushroom Cultivation guide 2020., April 20, 2018 https://agricultureguruji.com/mushroom-cultivation/.

[9] Vermicompost. https://en.wikipedia.org/wiki/Vermicompost (Page last edited 15 August 2020). 
[10] Tapuwa Justice Mashangwa (2018) The middlemen in agriculture: are they necessary? 7 Feb, https://www.chronicle.co.zw/the-middlemen-in-agricultureare-they-necessary/.

[11] Ila Patnaik and Shubho (2019) Want to help farmers, remove middlemen? Scrap the law governing agri markets 22 February, https://theprint.in/opinion/want-to-help-farmersremove-middlemen-scrap-the-law-governing-agrimarkets/196348/.

[12] Gunders, Dana. "Wasted: How America is Losing Up to 40 Percent of Its Food from Farm to Fork to Landfill." Natural Resources Defense Council, 2017. Retrieved March 7, 2019, from https://www.nrdc.org/sites/default/files/wasted-2017report.pdf.

[13] Dibyendu Mondal March 21, 2020 Food grains rot in FCI godowns every year. SundayGuardian Live, March 21, 2020.

[14] MK (Martin) van Ittersum Bridging yield gaps. Wageningen University \&Research,. https://www.wur.nl/en/show/Bridgingyield-gaps.htm.

[15] Amanda Barrell (2019) What are the pros and cons of GMO foods? Medical News Today (UK). https://www.medicalnewstoday.com/articles/324576.

[16] Shahbandeh M (2019) Percentage of genetically modified crops in the US, in 1997, 2018 and 2019 by type (as percentage of total acreage. Statista (Germany) https://www.statista.com/statistics/217108/level-ofgenetically-modified-crops-in-the-us/.

[17] Pyaralal Raghavan (2015) Does the devastation of Bt cotton crop in Punjab signal beginning of the end of a new technology? October, 10. https://timesofindia.indiatimes.com/blogs/minorityview/doesthe-devastation-of-bt-cotton-crop-in-punjab-signal-abeginning-of-the-end-of-a-new-technology/.

[18] Politecnico di Torino (2019) Seawater turns into freshwater through solar energy: A new low-cost technology. Science Daily 7 th January

https://www.sciencedaily.com/releases/2019/01/19010713124 2.htm.

[19] Rowan Jacobsen, (2016) Israel Proves the Desalination Era Is Here. Scientific American, Ensia conversation July 29. https://www.scientificamerican.com/article/israel-proves-thedesalination-era-is-here/.

[20] Jenny Howard (2019) Marine Pollution Explained. National geographic, August 2 https://www.nationalgeographic.com/environment/oceans/criti cal-issues-marine-pollution/.

[21] Kent Ro Systems (2017) The most polluted rivers of India. Feb. 13, https://www.kent.co.in/blog/the-most-polluted-riversof-india/.

[22] Jeff Carbeck 2019. Smarter fertilizers can reduce environmental contamination. Scientific American, December, P25.
[23] Seth Siegel (2017) The Secret of Israel's Water Miracle and How It Can Help a Thirsty World-Haaretz (Israel News, Tel Aviv) Editor Ruth Schuster. https://www.haaretz.com/scienceand-health/how-israel-can-help-a-thirsty-world-1.5392651.

[24] https://en.wikipedia.org/wiki/Urban_agriculture--Urban agriculture--Page last updated 24 March, 2020.

[25] FAO (UN) (2020) -Urban agriculture.

[26] Robotics Online Marketing Team (2017) Robotics in Agriculture: Types and Applications. https://www.robotics.org/blog-article.cfm/Robotics-inAgriculture-Types-and-Applications/74.

[27] Stephen Gossett (2020). Farming \& Agriculture Robots. Builtin Inc. (USA) https://builtin.com/robotics/farmingagricultural-robots.

[28] What are El Niño and La Niña? https://oceanservice.noaa.gov/facts/ninonina.html.

[29] $\mathrm{CO}_{2}$ emissions per capita / country wise (https://www.ucsusa.org/resources/each-countrys-share-co2emissions Jul 16, 2008 Updated Aug 12, 2020).

[30] Alina Bradford (2017) Effects of Global Warming - Live Science Contributor, Stephanie Pappas - Live Science Contributor August 12, https://www.livescience.com/37057global-warming-effects.html.

[31] Christina Nunez (2019) What is global warming, explained. National Geographic, January 22. https://www.nationalgeographic.com/environment/globalwarming/global-warming-overview/.

[32] Sustainable agriculturehttps://en.wikipedia.org/wiki/Sustainable_agriculture (page last edited on 20 August 2020).

[33] Brandon Miller (2019) 18 Advantages and Disadvantages of Organic Farming in Modern Agriculture Mar 19, https://greengarageblog.org/18-advantages-and-disadvantagesof-organic-farming-in-modern-agriculture.

[34] Mark Lynas (2018) New study challenges beliefs about organic ag. April https://allianceforscience.cornell.edu/blog/2018/04/new-studychallenges-beliefs-organic-ag/.

[35] Zero budget natural farming--- http://apzbnf.in/.

[36] https://www.worldometers.info/population/countries-in-africaby-population/.

[37] Monica Anderson and Phillip Connor (2018)-- Appendix D: Sub-Saharan African countries and territories-Pew Research Centre -Global attitudes and trends (Washington, USA) https://www.pewresearch.org/global/2018/04/24/sub-saharanafrican-countries-and-territories-sub-saharan-africanimmigrants-demographic-profile/. 